INSPIRAMATIKA | Jurnal Inovasi Pendidikan dan Pembelajaran Matematika Volume 5, Nomor 1, Juni 2019, ISSN 2477-278X, e-ISSN 2579-9061

\title{
PENGARUH MODEL PEMBELAJARAN KOOPERATIF TIPE CONCEPTUAL UNDERSTANDING PROCEDURES (CUPS) TERHADAP HASIL BELAJAR MATEMATIKA SISWA
}

\author{
Nia Arista Ardianti ${ }^{\mathrm{a}}$ \\ ${ }^{a}$ Program Studi Tadris Matematika, FTIK Institut Agama Islam Negeri Tulungagung \\ Jl.Mayor sujadi timur No 46 Tulungagung, niaarista181@gmail.com
}

\begin{abstract}
Abstrak
Penelitian ini bertujuan untuk mengetahui pengaruh model pembelajaran kooperatif tipe Conceptual Understanding Procedures (CUPs) terhadap hasil belajar matematika siswa kelas VII di SMP Negeri 1 Suruh tahun ajaran 2017/2018. Penelitian ini merupakan penelitian kuantitatif dengan desain quasi eksperimen. Populasi dalam penelitian ini adalah seluruh siswa kelas VII SMP Negeri 1 Suruh yang berjumlah 250 siswa. Dari populasi tersebut, sampel yang digunakan adalah kelas VII D sebanyak 23 siswa sebagai kelas eksperimen dan kelas VII E sebanyak 23 siswa sebagai kelas kontrol. Metode pengumpulan data yang digunakan adalah tes tertulis, observasi, dan dokumentasi. Instrumen yang digunakan adalah lembar tes tertulis, lembar observasi, dan lembar dokumentasi. Teknik analisis data yang digunakan adalah uji perbedaan rata-rata (uji-t) yang sebelumnya dilakukan uji normalitas dan uji homogenitasBerdasarkan hasil analisis diketahui bahwa sampel berdistribusi nomal dan homogen, serta ada pengaruh model pembelajaran kooperatif tipe Conceptual Understanding Procedures (CUPs) terhadap hasil belajar matematika siswa.
\end{abstract}

Kata Kunci : model pembelajaran kooperatif tipe Conceptual Understanding Procedures (CUPs), hasil belajar

\begin{abstract}
This study aims to determine the effect of cooperative learning model of Conceptual Understanding Procedures (CUPs) on the results of learning mathematics students of VII class in Junior High School 1 Suruh of 2017/2018 academic year. This research is a quantitative research with quasi experimental design. The population in this study were all students of VII class Junior High School 1 Suruh that amounts two hundred and fifty students. Of the population, the sample used is VII D class as many as twenty three students as the experimental class and VII E class as many as twenty three students as the control class. The data collection methods used was a written test, observation, and documentation. The instrument used was a written test sheet, observation sheet, and documentation sheet. Data analysis technique was test of average difference (t-test), but previously conducted tests of normality and homogenity. Based on the results of the analysis is known that the samples are normal and homogeny distributed, and there is influence of cooperative learning model of Conceptual Understanding Procedures (CUPs) on the results of learning mathematics students.
\end{abstract}

Keywords: cooperative learning model of Conceptual Understanding Procedures (CUPs), results of learning 


\section{PENDAHULUAN}

Matematika merupakan suatu alat untuk mengembangkan cara berpikir (Herman, 2005). Matematika tidak hanya dapat digunakan untuk mencapai satu tujuan, misalnya mencerdaskan siswa, tetapi dapat pula membentuk kepribadian siswa serta mengembangkan keterampilan tertentu. Karena itu matematika sangat diperlukan baik untuk kehidupan sehari-hari maupun dalam menghadapi kemajuan IPTEK sehingga matematika perlu dibekalkan kepada setiap peserta didik sejak SD, bahkan sejak TK (Herman, 2005).

Matematika perlu dibekalkan kepada setiap peserta didik sejak SD, bahkan sejak TK dengan tujuan agar matematika tidak dianggap lagi menjadi momok yang menakutkan bagi siswa. Pada kenyataannya, sampai saat ini masih banyak siswa beranggapan bahwa matematika adalah pelajaran yang menakutkan. Mereka berpikir matematika itu susah, rumit, kurang menarik, dan menjenuhkan yang mengakibatkan siswa tidak suka dengan pelajaran matematika. Padahal matematika diajarkan di berbagai jenjang sekolah dan siswa dituntut untuk mempelajari matematika agar dapat menghadapi perubahan keadaan sesuai dengan perkembangan dunia. Melalui pelajaran matematika siswa perlu menata nalarnya, membentuk kepribadiannya serta dapat menerapkan atau menggunakan matematika dalam kehidupannya kelak, sesuai dengan jenjang pendidikannya (Soedjadi, 2000). Banyak faktor yang berperan dalam mempengaruhi keberhasilan suatu pembelajaran termasuk matematika, diantaranya model dan metode pembelajaran yang digunakan, kemampuan awal siswa, kemampuan guru mengelola kelas, ketersedian waktu, media dan bahan ajar, motivasi belajar, hingga lingkungan pebelajar (Shodikin, 2015).

Oleh karena itu, diharapkan guru mampu mempersiapkan fasilitas belajar matematika sedemikian hingga siswa menjadi senang dan mempunyai perhatian terhadap materi matematika yang dipelajari. Dalam kaitan ini, tugas seorang guru adalah berupaya agar proses pembelajaran yang terjadi pada siswa berlangsung secara efektif (Asma, 2006). Selain itu, model pembelajaran yang digunakan guru juga harus disesuaikan dengan kemampuan siswa sehingga dapat membangkitkan minat siswa untuk belajar matematika.

Model pembelajaran merupakan kerangka konseptual yang melukiskan prosedur sistematis dalam mengorganisasikan pengalaman belajar untuk mencapai tujuan belajar. Fungsi dari model pembelajaran adalah sebagai pedoman bagi perancang pengajaran dan para guru dalam melaksanakan pembelajaran (Siswono, 2008). Salah satu model pembelajaran yang cocok digunakan 
adalah model pembelajaran Conceptual Understanding Procedures (CUPs). Menurut Gunstone, dkk. (2009), model pembelajaran Conceptual Understanding Procedures (CUPs) adalah suatu model pembelajaran yang bertujuan untuk membantu meningkatkan pemahaman konsep yang dianggap sulit oleh siswa. Conceptual Understanding Procedures (CUPs) berlandaskan pada pendekatan konstruktivisme, yaitu pendekatan pembelajaran yang mengajak siswa untuk berpikir dan mengkonstruksi dalam memecahkan suatu permasalahan secara bersama-sama, yang didasari pada kepercayaan bahwa siswa mengkonstruksi pemahaman konsep dengan memperluas atau memodifikasi pengetahuan yang sudah ada sehingga didapatkan suatu penyelesaian yang akurat. Model pembelajaran Conceptual Understanding Procedures (CUPs) mendorong siswa untuk berpikir secara aktif dan mengubah pandangan mereka sehingga menghasilkan partisipasi dan kepuasan tingkat tinggi. Fokus dari model pembelajaran Conceptual Understanding Prosedures (CUPs) yaitu untuk meningkatkan kualitas peranan aktif dan keterlibatan siswa baik secara intelektual maupun secara sosial dalam proses pembelajaran matematika di kelas.

Model pembelajaran Conceptual Understanding Procedures (CUPs) juga melibatkan nilai-nilai cooperative learning dan peran aktif siswa dalam proses pembelajaran. Menurut Slavin (dalam Sulistiawati, 2013), cooperative learning merajuk pada berbagai macam metode pengajaran dimana para siswa bekerja dalam kelompok-kelompok kecil untuk saling membantu satu sama lainnya dalam mempelajari materi pembelajaran. Dalam kelas kooperatif, para siswa diharapkan dapat saling membantu, saling berdiskusi dan beragumentasi untuk mengasah pengetahuan yang telah mereka kuasai sebelumnya dan menutup kesenjangan dalam pemahaman masing-masing.

Menurut Gunstone (2009), tahapantahapan dari model pembelajaran Conceptual Understanding Prosedures (CUPs) meliputi:

\section{Tahap 1 (Siswa bekerja secara individu)}

Siswa dihadapkan pada masalah matematika untuk dipecahkan secara individu.

\section{Tahap 2 (Siswa bekerja secara kelompok)}

Siswa dikelompokkan, setiap kelompok terdiri dari beragam kemampuan (tinggisedang-rendah) berdasarkan kategori yang dibuat oleh guru. Jumlah siswa dalam setiap kelompok mulai dari 2 sampai dengan 4 siswa. Setelah siswa dikelompokkan, setiap kelompok mendiskusikan permasalahan yang telah diberikan secara individu. Dalam pelaksanaan diskusi kelompok, guru mengelilingi kelas untuk mengklarifikasi hal-hal yang berkenaan dengan masalah bila 
diperlukan. Namun guru tidak terlibat lebih jauh dalam diskusi.

\section{Tahap 3 (Diskusi kelas)}

Pada tahap ini, hasil kerja triplet di tempel atau di pajang di depan kelas dan hasil diskusi kelompok dibahas bersama-sama. Selanjutnya guru melihat persamaan dan perbedaan jawaban siswa. Mungkin terdapat beberapa jawaban yang sama. Diskusi kelas dapat dimulai dengan memilih satu jawaban yang jawabannya dapat mewakili seluruh jawaban yang ada. Guru kemudian bertanya kepada anggota triplet yang jawabannya diambil untuk menjelaskan jawaban yang mereka buat. Jawaban yang berbeda dengan jawaban yang dipilih guru diminta juga untuk menjelaskannya. Berdasarkan kedua jawaban yang berbeda tersebut, siswa diminta untuk membuat argumentasi sendiri, sehingga dicapai kesepakatan yang dianggap sebagai hasil jawaban akhir siswa. Dalam tahapan ini guru belum menjelaskan jawaban yang sebenarnya. Selain itu pada proses ini siswa benar-benar dituntut untuk berpikir sehingga guru harus memperhatikan waktu tunggu sebelum memberikan pertanyaan lanjutan. Diakhir diskusi guru harus dapat melihat bahwa setiap siswa benar-benar menyadari (memegang) jawaban yang disetujui, dan bisa jadi siswa menuliskannya dalam kertas yang mereka pajang (tapi tanpa komentar yang lebih lanjut). Bila siswa tidak dapat mencapai kesepakatan, maka guru bisa menyimpulkan hasil diskusi, serta menyakinkan siswa bahwa kesimpulan ini dapat diterima.

Menurut Thobroni (2015), terdapat beberapa keunggulan dan kekurangan model pembelajaran Conceptual Understanding Procedures (CUPs), diantaranya yaitu:

a. Keunggulan

1. Memberi kesempatan kepada siswa untuk mengamati permasalahan secara individu sebelum berdiskusi dengan teman satu kelompoknya, sehingga dapat merangsang siswa untuk mengkonstruksi pengetahuannya sendiri terlebih dahulu.

2. Melatih siswa untuk ikut mengemukakan pendapat sendiri, menyetujui atau menentang pendapat teman-temannya.

3. Membina suatu perasaan tanggung jawab mengenai suatu pendapat, kesimpulan atau keputusan yang akan atau telah diambil.

4. Dengan melihat atau mendengarkan semua hasil permasalahan yang dikemukakan teman-temannya, pengetahuan siswa mengenai permasalahan tersebut akan bertambah luas.

b. Kekurangan

1. Membutuhkan waktu untuk persiapan pembelajaran.

2. Sangat penting bagi guru untuk memperhatikan waktu dalam 
pembelajaran individu, diskusi kelompok dan diskusi kelas.

3. Diskusi kelompok dan diskusi kelas mungkin didominasi oleh siswa yang memiliki kemampuan akademis tinggi dan berani atau telah biasa berbicara, sedangkan siswa yang memiliki kemampuan akademis sedang dan rendah atau pemalu tidak akan ikut berdiskusi dan berbicara dalam diskusi kelas

Belajar merupakan proses dalam diri individu yang berinteraksi dengan lingkungan untuk mendapatkan perubahan dalam perilakunya (Purwanto, 2009). Perubahan perilaku itu merupakan perolehan yang menjadi hasil belajar (Purwanto, 2009). Hasil belajar adalah perubahan perilaku siswa akibat belajar. Perubahan perilaku terjadi akibat penguasaan atas sejumlah bahan yang diberikan dalam proses belajar mengajar (Purwanto, 2009). Hasil belajar digunakan sebagai ukuran untuk mengetahui seberapa jauh seseorang menguasai bahan yang sudah diajarkan. Dapat dikatakan, hasil belajar matematika tergantung bagaimana pendidik menyampaikan materi dengan metode yang tepat. Jika pendidik menggunakan metode yang sesuai maka hasil belajar matematika akan meningkat. Hasil belajar siswa juga akan bisa dilihat bahwa siswa itu bisa menguasai materi dan memahami konsep serta kreatif dan aktif dalam menyelesaikan soal-soal matematika.

Penelitian ini bertujuan untuk mengetahui pengaruh model pembelajaran Conceptual Understanding Procedures (CUPs) terhadap hasil belajar matematika siswa kelas VII di SMP Negeri 1 Suruh. Penelitian ini didukung oleh penelitian sebelumnya yang dilakukan oleh Kartika (2013) yang bertujuan untuk mengetahui pengaruh model pembelajaran Conceptual Understanding Procedures (CUPs) terhadap pemahaman konsep dan hasil belajar matematika siswa kelas VII MTsN Tunggangri. Hasil penelitian tersebut menunjukkan bahwa pemahaman konsep dan hasil belajar siswa pada kelas eksperimen lebih tinggi dari pada kelas kontrol, dengan mencapai rata-rata 90,46 dari kriteria idealnya. Oleh karena itu, perlu dilakukan penelitian untuk mengetahui pengaruh model pembelajaran Conceptual Understanding Procedures (CUPs) terhadap hasil belajar matematika siswa pada kelas eksperimen dan kelas kontrol.

\section{METODE PENELITIAN}

Jenis penelitian ini adalah penelitian kuantitatif, dengan desain quasi eksperimen dengan kelompok kontrol tidak ekuivalen (Arifin, 2012). 
Tabel 1. Desain Kelompok Kontrol Tidak Ekuivalen

\begin{tabular}{llll}
\hline Kelompok & $\begin{array}{l}\text { Pre } \\
\text { Test }\end{array}$ & $\begin{array}{c}\text { Treat } \\
\text { Ment }\end{array}$ & $\begin{array}{c}\text { Post } \\
\text { test }\end{array}$ \\
\hline Eksperimen & $\mathrm{O}_{1}$ & $\mathrm{X}_{1}$ & $\mathrm{O}_{2}$ \\
Kontrol & $\mathrm{O}_{1}$ & $\mathrm{X}_{2}$ & $\mathrm{O}_{2}$ \\
\hline
\end{tabular}

Keterangan:

$\mathrm{O}_{1} \quad$ : Pretest

$\mathrm{X}_{1}$ : Pemberian treatment dengan model pembelajaran CUPs

$\mathrm{O}_{2} \quad$ : Postest

$\mathrm{X}_{2} \quad$ : Pemberian treatment dengan model pembelajaran konvensional

Populasi dalam penelitian ini adalah seluruh siswa kelas VII SMP Negeri 1 Suruh yang berjumlah 250 siswa. Dari populasi tersebut, sampel yang digunakan adalah kelas VII D sebanyak 23 siswa sebagai kelas eksperimen dan kelas VII E sebanyak 23 siswa sebagai kelas kontrol. Variabel dalam penelitian ini, meliputi Model Pembelajaran Kooperatif tipe Conceptual Understanding Procedures (CUPs) sebagai variabel independen dan hasil belajar sebagai variabel dependen.

Metode pengumpulan data yang digunakan dalam penelitian ini berupa tes tertulis yang digunakan untuk mengetahui seberapa jauh pemahaman siswa terhadap materi yang telah diajarkan oleh guru; observasi digunakan untuk mengamati secara langsung kegiatan pembelajaran di kelas; dan dokumentasi ditujukan untuk memperoleh data langsung dari tempat penelitian, meliputi buku-buku yang relevan, foto-foto, film dokumenter, dan lain sebagainya. Instrumen yang digunakan dalam penelitian ini berupa lembar tes tertulis yang digunakan untuk mengetahui perbedaan hasil belajar matematika siswa yang diberikan perlakuan model pembelajaran CUPs (kelas eksperimen) dengan hasil belajar matematika siswa pada kelas yang tidak diberi perlakuan model pembelajaran CUPs (kelas kontrol); lembar observasi digunakan untuk mengamati proses kegiatan belajar mengajar sehingga dapat diketahui secara langsung hasil dari penerapan model pembelajaran CUPs; dan lembar dokumentasi digunakan untuk melengkapi data-data dalam penelitian sehingga bisa memperkuat laporan hasil penelitian.

Penelitian ini menggunakan analisis data kuantitatif. Adapun statistik yang digunakan adalah Uji Perbedaan Rata-Rata (Uji-t). Untuk menguji hipotesis (uji t) sebelumnya harus memenuhi: (1) Uji normalitas yang bertujuan untuk memperlihatkan bahwa data sampel berasal dari populasi yang berdistribusi normal. Untuk menguji normalitas data dapat menggunakan uji Kolmogorov Smirnov dengan ketentuan jika Asymp.sig $\geq 0,05$ maka data tersebut berdistribusi normal; (2) Uji homogenitas digunakan untuk menguji apakah data yang diuji dalam sebuah penelitian itu merupakan data yang homogen atau tidak. Rumus untuk menguji homogenitas adalah $F_{\text {max }}=\frac{\text { Varians Tertinggi }}{\text { Varians Terendah }}$ (3) Uji hipotesis digunakan untuk mengetahui pengaruh model pembelajaran 
Conceptual Understanding Procedures (CUPs) terhadap motivasi dan hasil belajar matematika siswa dengan menggunakan uji t. Langkah-langkah uji t, meliputi: membuat hipotesis dalam bentuk kalimat dan statistik, menentukan dasar pengambilan keputusan berdasarkan signifikan dan z-hitung, dan membuat kesimpulan. Rumus uji t tersebut adalah $t$-test $=\frac{\overline{\mathrm{x}}_{1}-\overline{\mathrm{X}}_{2}}{\sqrt{\frac{\mathrm{s}_{1}^{2}}{\mathrm{n}_{1}}+\frac{\mathrm{s}_{2}^{2}}{\mathrm{n}_{2}}}}$

\section{HASIL DAN PEMBAHASAN}

\section{Normalitas Data}

Dalam pengujian ini peneliti menguji normalitas guna melihat data yang diujikan berdristibusi normal atau tidak. Data yang digunakan diambil dari hasil postest pada kelas eksperimen dan kelas kontrol. Dalam uji normalitas terdapat kriteria yaitu jika taraf siginifikansi $(\mathrm{sig}) \geq 0,05$ maka $\mathrm{H}_{0}$ ditolak berarti data berdistribusi normal. Sedangkan, jika taraf siginifikansi (sig) < 0,05 maka $\mathrm{H}_{0}$ diterima, berarti data berdistribusi tidak normal.

Tabel 2. Tests of Normality

\begin{tabular}{|l|c|c|c|c|c|c|}
\hline \multirow{2}{*}{} & \multicolumn{3}{|c|}{ Kolmogorov-Smirnov $^{\mathrm{a}}$} & \multicolumn{4}{|c|}{ Shapiro-Wilk } \\
\cline { 2 - 7 } & Statistic & Df & Sig. & Statistic & Df & Sig. \\
\hline Eks & .173 & 23 & .074 & .913 & 23 & .047 \\
Kon & .169 & 23 & .087 & .924 & 23 & .080 \\
\hline
\end{tabular}

a. Lilliefors Significance Correction

Berdasarkan Tabel 2, diketahui bahwa nilai signifikan dari kelas eksperimen adalah 0,074, sedangkan pada kelas kontrol adalah 0,087. Dari hasil tersebut telihat bahwa kedua data berdistribusi normal.

\section{Uji Homogenitas}

Uji homogenitas berfungsi untuk menguji apakah kedua sampel memiliki varian yang sama atau tidak. Data yang digunakan diambil dari hasil postest pada kelas eksperimen dan kelas kontrol. Dengan kriteria jika nilai signifikan $(\mathrm{sig}) \geq 0,05$ maka $\mathrm{H}_{0}$ ditolak berarti data homogen dan jika nilai signifikan (sig) $<0,05$ maka $\mathrm{H}_{0}$ diterima, berarti data tidak homogen.

Tabel 3. Test of Homogeneity of Variances

\begin{tabular}{|c|c|c|c|}
\hline Levene Statistic & $\mathrm{df1}$ & $\mathrm{df} 2$ & Sig. \\
\hline 2.000 & 5 & 14 & .141 \\
\hline
\end{tabular}

Berdasarkan Tabel 3, diketahui bahwa nilai signifikan $(\mathrm{sig})=0,141$. Karena nilai signifikan dari data tersebut lebih besar dari 0,05 maka data tersebut dinyatakan homogen.

\section{Uji Perbedaan Rata-rata}

Dari hasil perhitungan yang dicantumkan pada penjelasan di atas, menunjukkan bahwa masing-masing variabel dalam penelitian tersebut memenuhi persyaratan kelayakan untuk dapat diujikan lebih lanjut menggunakan uji-t. Data yang didapat oleh peneliti berdasarkan hasil tes yang diberikan. Dengan kaidah pengujian jika nilai sig (2tailed) $>0,05$, maka $\mathrm{H}_{0}$ diterima dan jika nilai sig (2-tailed $) \leq 0,05$, maka $\mathrm{H}_{0}$ ditolak. 
Tabel 4. Independent Samples Test

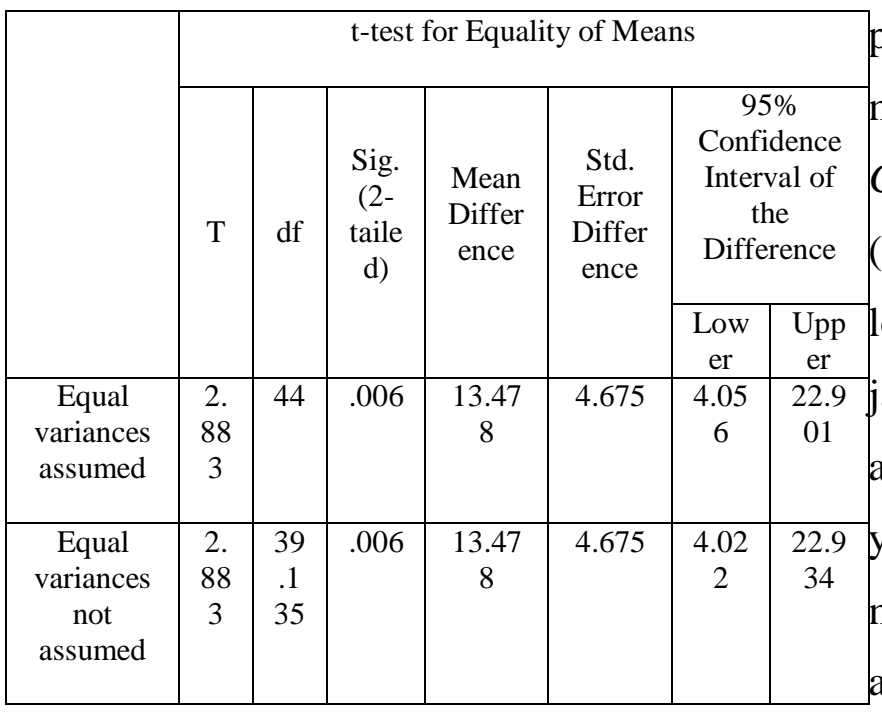

Berdasarkan Tabel 4, diketahui bahwa nilai sig (2-tailed) adalah 0,006 sehingga dapat dituliskan nilai sig (2-tailed) $<$ taraf signifikansi $(0,05$ atau 5\%) $=0,006<$ 0,05. Ini berarti bahwa nilai sig (2-tailed) lebih kecil dari pada taraf signifikansi $5 \%$. Dengan demikian, $\mathrm{H}_{0}$ ditolak dan $\mathrm{H}_{1}$ diterima yang berarti terdapat perbedaan yang signifikan antara rata-rata postest siswa yang diajar dengan menggunakan model pembelajaran kooperatif tipe Conceptual Understanding Procedures (CUPs) dengan menggunakan model pembelajaran konvensional. Hal ini menunjukkan adanya pengaruh model pembelajaran kooperatif tipe Conceptual Understanding Procedures (CUPs) terhadap hasil belajar matematika siswa.

Berdasarkan keterangan tersebut dapat disimpulkan bahwa pembelajaran dengan model pembelajaran kooperatif tipe Conceptual Understanding Procedures
(CUPs) lebih baik dibandingkan dengan pembelajaran konvensional. Dengan adanya model pembelajaran kooperatif tipe Conceptual Understanding Procedures (CUPs) pada pembelajaran siswa menjadi lebih kreatif dalam menemukan jawabanjawaban dari suatu permasalahan dan lebih aktif dalam bertukar pendapat dengan teman yang lain, dengan kerjasama siswa dapat mengembangkan pengetahuan, serta dengan adanya diskusi kelas siswa menjadi lebih aktif dan dapat mengambil kesimpulan sendiri hasil jawaban dari suatu permasalahan sehingga siswa paham betul dengan materi yang telah dipelajari.

Berdasarkan hasil pengamatan terlihat bahwa siswa yang berada di kelas eksperimen lebih fokus pada pelajaran daripada siswa yang berada di kelas kontrol. Hal ini ditunjukkan dengan seriusnya siswa dalam menyelesaikan masalah baik secara individu maupun kelompok, dan antusias siswa dalam berpresentasi di depan kelas terkait hasil diskusinya saat diskusi kelas.

\section{KESIMPULAN DAN SARAN}

Berdasarkan hasil dan pembahasan di atas, dapat disimpulkan bahwa ada pengaruh model pembelajaran kooperatif tipe Conceptual Understanding Procedures (CUPs) terhadap hasil belajar matematika siswa kelas VII SMP Negeri 1 Suruh tahun ajaran 2017/2018. Berdasarkan hasil perhitungan menggunakan SPSS 16.0 untuk 
hasil belajar diperoleh nilai sig (2-tailed $)=$ $0,006<$ taraf signifikansi $(0,05)$ yang menyatakan bahwa ada perbedaan hasil belajar matematika siswa yang diberi perlakuan pada kelas eksperimen dan yang tidak diberi perlakuan pada kelas kontrol.

Demi kemajuan dan keberhasilan proses belajar mengajar dalam rangka meningkatkan kualitas pembelajaran, diharapkan peneliti berikutnya dapat mengembangkan pengetahuannya yang berkaitan dengan belajar siswa dan mampu mencari metode yang tepat dalam pembelajaran khususnya lebih memantapkan lagi pembelajaran tipe Conceptual Understanding Procedures (CUPs) sehingga siswa menjadi lebih aktif dan tercipta suasana yang menyenangkan dalam pembelajaran.

\section{DAFTAR PUSTAKA}

Arifin, Z. (2012). Metodologi Penelitian Pendidikan Matematika. Surabaya: Lentera Cendekia.

Asma, N. (2006). Model Pembelajaran Kooperatif. Jakarta : Departemen Pendidikan Nasional Dorektorat Jenderal Pendidikan Tinggi Direktorat Ketenagaan.

Gunstone, D., McKittrick, B., \& Milhall, P. (2009). CUP - A Procedure for Developing Conceptual Understanding. Prosiding PEEL Conference. Australia: Monash University.

Herman, Hudojo. (2005). Pengembangan Kurikulum \& Pembelajaran Matematika.Malang : UM Press.

Kartika, M. (2013). Pengaruh model pembelajaran
Understanding Procedures (CUPs) terhadap pemahaman konsep dan hasil belajar matematika siswa kelas VII MTsN Tunggangri. Tidak dipublikasikan. Tulungagung: Institut Agama Islam Negeri Tulungagung.

Purwanto. (2009). Evaluasi Hasil Belajar. Yogyakarta: Pustaka Pelajar.

Shodikin, A. (2015). Interaksi Kemampuan Awal Matematis Siswa dan Pembelajaran Dengan Strategi Abduktif-Deduktif Terhadap Peningkatan Kemampuan Penalaran dan Disposisi Matematis Siswa. Inspiramatika. Vol 1(1), pp. 61-72.

Siswono, T.Y.E. (2008). Model Pembelajaran Matematika Berbasis Pengajuan dan Pemecahan Masalah untuk Meningkatkan Kemampuan Berpikir Kreatif. Surabaya: Unesa University Press.

Soedjadi, R. (2000). Kiat Pendidikan Matematika di Indonesia. Jakarta: Departemen Pendidikan Nasional.

Sulistiawati. (2019). Penerapan Model Pembelajaran Cooperatif Learning Tipe Make a Match Untuk Meningkatkan Hasil Belajar Aqidah Akhlak Pada Siswa Kelas III MI Ypi Umbul Bandung Desa Tanjung Ratu Kec. Katibung Tahun Pelajaran 2018/2019. Skripsi. Fakultas Tarbiyah dan Keguruan Universitas Islam Negeri (Uin) Raden Intan Lampung.

Thobroni. (2015). Keunggulan \& Kelemahan Model Pembelajaran CUPs. Diakses dari laman web tanggal 15 April 2019 dari: http://smartgeografi.blogspot.co.id/2 015/06/keunggulan-kelemahanmodel - cups.html?m=1 